\title{
ÁGUA POTÁ VEL E SANEAMENTO BÁSICO: O ENCONTRO NECESSÁRIO DE DOIS DIREITOS FUNDAMENTAIS À SAÚDE DA VIDA EM GERAL
}

\author{
Ana Alice De Carli * \\ Leonardo de Andrade Costa *
}

\section{Resumo}

No presente texto objetiva-se trazer à discussão dois temas que estão intrinsicamente imbricados. Trata-se dos direitos à água potável e ao saneamento básico, porquanto sem o necessário implemento dos adequados serviços de coleta e tratamento de esgotos não se terá manancial hídrico com qualidade, a despeito da existência de significativo potencial de água em solo brasileiro. Sob a perspectiva metodológica, o estudo ampara-se em pesquisa exploratória, com elementos qualitativos e quantitativos.

Palavras-chave: Direitos Fundamentais; Água; Saneamento Básico; Sustentabilidade; Natureza.

\section{DRINKING WATER AND SANITATION: THE MEETING OF TWO FUNDAMENTAL RIGHTS TO HEALTH OF LIFE IN GENERAL}

\begin{abstract}
This text aims to bring to the discussion two themes that are intrinsically intertwined. These are the rights to drinking water and basic sanitation, since without the necessary implementation of the appropriate sewage collection and treatment services there will be no quality water supply, despite the existence of significant water potential in Brazilian soil. From the methodological perspective, the study is based on exploratory research, with qualitative and quantitative elements.
\end{abstract}

Keywords: Fundamental Rights; Water; Basic Sanitation; Sustainability; Nature.

\section{1ntrodução}

O presente artigo tem por objetivo geral problematizar o necessário imbricamento entre o acesso ao direito fundamental à água potável e o direito fundamental ao saneamento básico (aqui compreendido - em síntese - como um conjunto de serviços de coleta e

\footnotetext{
* Doutora e Mestre em Direito Público e Evolução Social. Professora Adjunta da Universidade Federal Fluminense. Coordenadora da Pós-Graduação Lato Sensu em Residência Jurídica, UFF/VR. Autora de livros jurídicos. Membro da Comissão de Meio Ambiente da OAB/RJ. Pesquisadora-lider do Grupo de Estudos em Meio Ambiente e Direito - GEMADI/UFF. Email: anacarli@id.uff.br

* Doutorando em Direito da Regulação pela FGV/Direito/Rio. Mestre em Direito pela Harvard University/ USP. Professor da Escola de Direito FGV/Rio. Auditor Fiscal do Estado do Rio de Janeiro. Email: Leonardo.costa@fgv.br
} 
tratamento de esgoto, de políticas de resíduos sólidos e de tratamento e distribuição equânime de água boa).

Nesse diapasão, tem-se por desiderato demonstrar, à guisa de questão nuclear deste estudo, que a promoção de práticas de saneamento básico é conditio sine qua non para que se tenha - efetivamente - mananciais de água com qualidade. Assim, sob a perspectiva metodológica, adotar-se-á a pesquisa exploratória, com elementos qualitativos e quantitativos.

Apesar de ainda não ser um fato claro e definitivo para todas as pessoas de que a água é um bem finito e que depende - e muito - de ações não somente sob a perspectiva do seu uso racional - que também é fundamental para a sua preservação -, mas sobretudo de políticas de implemento do direito ao saneamento básico. Dito de outra forma: além das pessoas, a água (e a natureza em sua plenitude) também precisa ser protegida com ações sustentáveis, a partir de mudanças de comportamento e com o desenvolvimento de instrumentos tecnológicos que tornem a implantação dos serviços de saneamento básico mais barata e para todos.

O termo "saneamento básico" traduz por si só a sua relevância para a saúde de muitas formas de vida. Aliás, vale ressaltar que a Organização das Nações Unidas (ONU) já elevou ao patamar de direitos humanos, a água e o saneamento básico. Em 2009, aprovou a Resolução ${ }^{\circ}$ 12/8, por meio da qual reconheceu a obrigação dos Estados de promover ações voltadas para solucionar problemas relacionados à precarização - ou falta - dos serviços de saneamento básico. Em seguida, em 2010, por meio da Resolução n 64/292, aprovada em 28 de julho 2010, em sua $108^{\text {a }}$ Reunião Plenária, a ONU reconheceu formalmente o direito ao saneamento e à água potável como direito humano fundamental (UN. Resolução n. 64/292. www.un.org/ga/search/view_doc.asp?symbol=A/RES/64/292, 01.02.2019).

Depois, em 2015, na sua $80^{\mathrm{a}}$ Reunião Plenária, a ONU editou a Res. 70/169, reconhecendo que os direitos à água potável e ao saneamento básico são direitos fundamentais autônomos. Conforme se extrai de parte do texto do referido documento:

Recalling the understanding by the Committee on Economic, Social and Cultural Rights and the Special Rapporteur on the human right to safe drinking water and sanitation that the rights to safe drinking water and sanitation are closely related, but have distinct features which warrant their separate treatment in order to address specific challenges in their implementation (UN. Res. 70/169. <http://www.un.org/en/ga/search/view_doc.asp?symbol=A/RES/70/169, 27.02.2019, p.4) ${ }^{1}$.

De fato, a despeito de a qualidade da água depender essencialmente do implemento do direito ao saneamento básico, por meio de ações efetivas, envolvendo adequados sistemas de coleta e de tratamento de esgoto - entre outros aspectos -, tais direitos devem ter regimes jurídicos distintos. A água (ou melhor das águas, porquanto há vários tipos de água: ex. água doce, agua salobra, água salgada, água mineral) consubstancia um bem ambiental natural, finito e insubstituível, visto que a tecnologia pode criar muitos bens e serviços, inclusive semelhantes, mas não consegue, em hipótese alguma, criar água, sendo possível apenas captar o líquido por meio de tecnologias. Â guisa de ilustração cabe trazer alguns exemplos, a começar pela brilhante ideia do holandês Piet Oosterling, que desenvolveu uma técnica de

\footnotetext{
1 Tradução livre: "considerando o entendimento do Comitê de direitos econômicos, sociais e culturais e, especialmente, o relatório sobre o direito humano à água potável e ao saneamento, que reconhece que tais direitos, embora são intimamente vinculados, possuem distintas características, implicando desse modo tratamentos dieferentes, com vistas a enfrentar desafios específicos em sua implementação".
} 
captação de água por meio do vento, com a utilização de turbinas eólicas. Segundo o pesquisador em tela, tal tecnologia pode produzir diariamente cerca de 7.500 litros de água (CAMARGO , 2019). Outro exemplo que merece destaque vem de perto, trata-se de uma técnica ainda em desenvolvimento, conforme pontua a pesquisadora Pilar Cereceda, a qual está sendo implantada na cidade costeira do Chile, Chañaral. A água é captada da neblina por meio de painéis - "atrapanieblas" - (GASPAR, 2019). As inovações tecnológicas, como demonstram os exemplos aqui mencionados, nem sempre dependem de capital financeiro elevado para serem implantadas, dependendo, sim, de vontade política e consciência ecológica de que sem o ouro azul ${ }^{2}$ não há vida, tampouco desenvolvimento econômico.

Neste ano de 2019, para celebrar o dia mundial da água, a ONU lançou a campanha "Water for all - leaving no one behind" (água para todos, sem deixar ninguém pra trás), o que sinaliza o esforço de se garantir que o acesso ao líquido precioso com qualidade seja para todos.

\section{2. Água, bem da vida insubstituível}

Conforme já mencionado acima, a água é um bem finito, sendo essencial para a vida do e no planeta terra, razão pela qual desde a época do doutoramento tem-se defendido a necessidade de se reconhecer a água como sujeito de direitos e de dignidade (CARLI, 2013), o que implicaria, em um primeiro momento, necessidade de mudanças de paradigmas não apenas para os indivíduos, mas sobretudo para o direito, que precisaria se atualizar para adaptar seus institutos ou - até mesmo - criar significantes próprios para promover com efetividade a tutela das águas e da natureza em sua plenitude. Ainda nesse diapasão, há de se ter como premissa básica a aplicação do princípio da igualdade material no cenário das águas; ou seja, os atores sociais precisam aprender com muitos povos, a exemplo dos indígenas, a olhar para a natureza com respeito e cuidado.

Já na Antiguidade constata-se que muitos pensadores têm analisado os fundamentos do Direito e de sua função construtora e reguladora do mundo da vida (SABADEL, 2008). Hodiernamente, o estudo dos fundamentos do direito continua sendo objeto de estudo. A complexidade das sociedades na contemporaneidade exige das Ciências Jurídicas respostas nem sempre fáceis e livres de críticas. A ideia do positivismo clássico, por exemplo, calcado no método de subsunção do fato à norma, encontra na atualidade objeções por parte da doutrina (GRAU, 2009), porquanto nem sempre é possível examinar um fato da vida aplicando simplesmente o método subsuntivo, na medida em que nem todos os fatos estão contidos no quadro emoldurado do direito. Nesse sentido, pontua Pietro Perlingieri (2007, p. 68):

A ampliação da noção de direito positivo e a sua abertura para noções e valores não literalmente e não explicitamente subsuntos nos textos jurídicos permite a superação da técnica da subsunção e a prospecção mais realística dialética e de integração fato-norma em uma acepção unitária da realidade.

Na linha de preleção do mencionado autor, entende-se que a análise de um caso concreto deve levar em conta não somente o direito posto, mas sobretudo critérios de justiça que considerem os valores a serem protegidos: no estudo em tela o valor maior que se busca proteger é a água e, por conseguinte, a saúde do e no planeta terra.

\footnotetext{
${ }^{2}$ Expressão cunhada pelos autores na obra: BARLOW, Maude; CLARKE, Tony. Ouro Azul: como as grandes corporações estão se apoderando da água doce do nosso planeta. São Paulo: Editora M. Books do Brasil, 2003.
}

Rev. de Direito e Sustentabilidade | e-ISSN: 2525-9687 | Evento Virtual | v. 6 | n. 1 | p. 1-15 | 
Caminhar na direção do reconhecimento da água como sujeito de direitos implicaria pelo menos - estimular as pessoas para um despertar ecológico, com o qual poderiam surgir novos atores sociais em prol da proteção e da preservação do ouro azul, sem descuidar de que todos, indistintamente, poderiam se tornar tutores das águas, com vistas a assegurar sua qualidade, quantidade e dignidade.

Nesse contexto, imagine-se uma situação simples - mas não insignificante sob o ponto de vista da preservação dos recursos hídricos -, na qual um indivíduo se depara com alguém limpando a calçada de sua casa ou de seu estabelecimento comercial com uma mangueira com água; ou seja, o líquido precioso é usado para varrer o chão. Assim, a partir da ideia de que todos seriam tutores das águas, poderia aquele cidadão orientá-lo sobre a importância do cuidado à manutenção do elemento essencial para a vida, ou, ainda, dependendo da situação, representar junto aos órgãos públicos e até ajuizar uma ação popular. Com efeito, no âmbito do agronegócio, em que o uso de recursos hídricos é deveras acentuado, os empreendedores poderiam investir mais em tecnologias de reuso e captação de águas.

Nesse sentido, é possível pensar na existência de três categorias de direitos envolvendo a água, seriam elas: direito à água (como um direito fundamental de todos os seres vivos: pessoas, fauna e flora); direito de águas (como um conjunto de normas que disciplina os diferentes tipos de águas - trata-se de regimes jurídicos distintos de acordo com a água; ex. água doce, oceanos, água mineral) e o direito das águas (trata-se de um direito fundamental de as águas serem protegidas contra as ações antrópicas e da própria natureza.

A Declaração Universal dos Direitos da Água (〈www.ecolnews.com.br〉, 2020) da ONU, de $1992^{3}$, sinaliza no sentido da possibilidade de existência da categoria fundamental de direitos das águas - estas como sujeitos de direitos. De modo que, conforme já pontuado anteriormente, o homem ocuparia duas posições distintas: a de predador e a de defensor das águas. Veja-se parte do texto do referido documento:

(...)7. A água não deve ser desperdiçada, nem poluída, nem envenenada. De maneira geral, sua utilização deve ser feita com consciência e discernimento para que não se chegue a uma situação de esgotamento ou de deterioração da qualidade das reservas atualmente disponíveis.

8.-A utilização da água implica em respeito à lei. Sua proteção constitui uma obrigação jurídica para todo homem ou grupo social que a utiliza. Esta questão não deve ser ignorada nem pelo homem nem pelo Estado.

9.-A gestão da água impõe um equilíbrio entre os imperativos de sua proteção e as necessidades de ordem econômica, sanitária e social (www.ecolnews.com.br, 2020).

O reconhecimento do direito das águas no atual contexto, em que há exponencial demanda por bens e serviços, implicando contínuo aumento de consumo e de resíduos, faz-se necessário e, ainda, cotejar a proteção do líquido vital com a concretização de outro direito fundamental, o saneamento básico, pois, sem os quais não há que se falar em meio ambiente saudável e equilibrado, nos termos do art. 225 da Constituição Federal de 1988.

Ainda, vincular o acesso aos direitos fundamentais ao saneamento básico e à água com qualidade é condição sine qua non para melhorar a saúde de todas as formas de vida. Segundo dados do relatório do Programa de Monitoramento Conjunto - Progress on drinking water, sanitation and hygiene: 2017 update and Sustainable Development Goal baselines, cerca de:

\footnotetext{
${ }^{3}$ Dia 22 de março de 1992 é considerado, de acordo com a ONU (Organização das Nações Unidas), o "Dia Mundial da Água", o qual vem sendo celebrado por Estados, Organizações governamentais e nãogovernamentais, outros segmentos sociais, além de pesquisadores e acadêmicos em geral.
} 
2,1 bilhões pessoas não possuem água gerenciada de forma segura, 844 milhões não têm nem um serviço básico de água potável. Isso inclui 263 milhões de pessoas que precisam gastar mais de 30 minutos por viagem para coletar água de fontes distantes de casa e 159 milhões que ainda bebem água não tratada de fontes de água superficiais, como córregos ou lagos (OPAS BRASIL, 2019).

Sem descuidar do fato de que, em regra, para cada 1 real investido em serviços de saneamento básico tem-se uma economia em gastos com saúde de cerca de 4 reais, segundo Conceicao de Maria Albuquerque Alves, que, consoante matéria do Correio Braziliense, "doenças relacionadas à água causam 3,5 milhões de mortes a cada ano na América Latina, na África e na Ásia. Um número superior à soma de mortes por acidentes de carros" (2019). E como enfatizado aqui, a qualidade da água está intrinsecamente relacionada à implementação de adequados serviços de saneamento básico e de forma universal.

\section{Saneamento básico: necessidade premente na atualidade}

Já na década de 1980 no Brasil, renomados defensores do equilíbrio ecológico já pontuavam sobre questões envolvendo qualidade da água e saneamento básico. Destacam nesse sentido o surgimento, em 1971, da primeira associação de proteção ao meio ambiente natural. Trata-se da Associação Gaúcha de Proteção ao Meio Ambiente (Agapan), fundada, entre outros, pelo engenheiro agrônomo José Lutzenberger. Sobre o programa desta associação, Eduardo Viola (VIOLA, 1987, p. 66-110) ressalta alguns pontos relevantes, a exemplo do "combate indiscriminado de inseticidas, fungicidas e herbicidas" (como se pode constatar a questão do uso de agrotóxicos já era objeto de preocupação naquela época. E hoje, 39 anos depois?), e o "combate à poluição dos cursos d'água pelos resíduos industriais e domiciliares não tratados".

Em outro trabalho (CARLI, 2013), ao se examinar a Lei Nacional das Águas (Lei ${ }^{\circ}$ 9.433/97), questionou-se a existência de dispositivo que ainda permite o descarte de efluente sem tratamento nos mananciais de água - o que, por certo, não apenas viola os direitos à água e das águas, como também serve de instrumento "deseducador" ambiental, pois se os rios podem servir de depósito de esgotos industriais e domésticos, em tese, podem também servir de descarte de outros objetos, como seguidamente se visualiza a existência de sofás, pneus etc. À guisa de ilustração, vale transcrever a mencionada normativa da Lei no 9.433/97:

Art. 12. Estão sujeitos a outorga pelo Poder Público os direitos dos seguintes usos de recursos hídricos:

[...]

III - lançamento em corpo de água de esgotos e demais resíduos líquidos ou gasosos, tratados ou não, com o fim de sua diluição, transporte ou disposição final (sem grifo no original).

Conforme se verifica no inciso III, do dispositivo acima transcrito, a Lei das Águasrepise-se - ainda admite o lançamento em corpos de água de esgotos não tratados. Entende-se que tal norma viola a Constituição Federal de 1988 (ar. 225) e, bem assim, os direitos das águas. Desse modo, buscando construir uma interpretação provisória para este problema, defende-se que esta previsão legislativa se encontra em estado de inconstitucionalidade progressiva $^{4}$, pois à medida em que houver a implantação plena do esgotamento sanitário, por

\footnotetext{
${ }^{4}$ A inconstitucionalidade progressiva (a lei é ainda constitucional) "é a que decorre da falta de implementação das estruturas normativas previstas na Constituição", ensina Uadi Lammego Bulos, in: BULOS, Uadi Lammego. Curso de Direito Constitucional. 5 ed. São Paulo: Editora Saraiva, 2010,p. 158.
}

Rev. de Direito e Sustentabilidade | e-ISSN: 2525-9687 | Evento Virtual | v. 6 | n. 1 | p. 1-15 | 
meio de políticas efetivas de saneamento básico, não haverá mais espaço normativo permissivo para lançamentos de esgotos não tratados nos mananciais.

Vale acentuar que a outorga de uso de recursos hídricos é um dos instrumentos da Política Nacional de Recursos Hídricos (art.5 ${ }^{\circ}$, inciso III, da Lei $n^{\circ}$ 9.433/97) e a sua concessão está sujeita, nos termos da legislação em comento, ao seu potencial disponível em cada ocasião - considerando-se as épocas de escassez e "as prioridades de uso estabelecidas nos Planos de Recursos Hídricos e deverá respeitar a classe em que o corpo de água estiver enquadrado [...]" (art. 13).

A expressão saneamento básico sinaliza a necessidade de existência de medidas voltadas para promover melhorias na vida e na saúde dos seres vivos, implicando o combate de agentes prejudiciais a esses direitos. Nesse sentido, priorizar - o que já devia ser notadamente priorizado - os serviços de coleta e tratamento adequado de esgoto, somados à efetiva coleta seletiva e o descarte de resíduos, compreendem conditio sine qua non à qualidade da vida em todas as suas formas.

Para a Organização Mundial de Saúde (OMS) a noção de saneamento básico contempla o acesso e, bem assim, o uso de instalações e serviços para a eliminação segura de fezes e urina humana. Entretanto, como será visto, o significado de saneamento básico é bem mais amplo, em particular no ordenamento jurídico brasileiro, nos termos do estabelecido na Lei $\mathrm{n}^{\circ} 11.445 / 07$, em seu art. $2^{\circ}$, modificado pela Medida Provisória $\mathrm{n}^{\circ} 868$, de 28 de dezembro de 2018:

Art. $2^{\circ}$ Para fins do disposto nesta Lei, considera-se:

I-A - saneamento básico - conjunto de serviços, infraestruturas e instalações operacionais de:

a) abastecimento de água potável, constituído pelas atividades, pela disponibilização, pela manutenção, pela infraestrutura e pelas instalações necessárias ao abastecimento público de água potável, desde a captação até as ligações prediais e os seus instrumentos de medição;

b) esgotamento sanitário, constituído pelas atividades, pela disponibilização e pela manutenção de infraestrutura e das instalações operacionais de coleta, transporte, tratamento e disposição final adequados dos esgotos sanitários, desde as ligações prediais até a sua destinação final para a produção de água de reuso ou o seu lançamento final no meio ambiente;

c) limpeza urbana e manejo de resíduos sólidos, constituídos pelas atividades, pela infraestrutura e pelas instalações operacionais de coleta, transporte, transbordo, tratamento e destinação final ambientalmente adequada dos resíduos sólidos domiciliares e dos resíduos de limpeza urbanas; e

d) drenagem e manejo das águas pluviais urbanas, constituídos pelas atividades, pela infraestrutura e pelas instalações operacionais de drenagem de águas pluviais, de transporte, detenção ou retenção para o amortecimento de vazões de cheias, tratamento e disposição final das águas pluviais drenadas, contempladas a limpeza e a fiscalização preventiva das redes (...).

O que de fato mudou em relação ao aspecto conceitual previsto da normativa acima, a partir da Medida Provisória n ${ }^{\circ} 868 / 2018^{5}$ ?

\footnotetext{
${ }^{5}$ Vale mencionar que o atual cenário mudou um pouco, visto que no dia 15 de julho de 2020 o Presidente da República do Brasil sancionou a lei do novo marco regulatório do saneamento básico. O texto foi para publicação com 11 vetos, os quais ainda não se sabe se serão mantidos pelo Parlamento Federal. O novo diploma legal estabelece como meta o dia 31 de dezembro de 2033 para a universalização dos serviços de saneamento.
} 
Para melhor compreensão, segue o quadro sinóptico:

\begin{tabular}{|c|c|}
\hline Lei $^{\circ}{ }^{\circ} 11.445 / 07$ antes da MP n ${ }^{\circ} 868 / 2018$ & $\begin{array}{l}\text { Lei } \mathrm{n}^{\circ} 11.445 / 07 \text { depois da edição da MP } \mathrm{n}^{\circ} \\
868 / 2018\end{array}$ \\
\hline $\begin{array}{l}\text { Art. } 2^{0} \text { Para os efeitos desta Lei, considera-se: } \\
\text { I - saneamento básico: conjunto de serviços, } \\
\text { infra-estruturas e instalações operacionais de: }\end{array}$ & $\begin{array}{l}\text { Art. } 2^{\circ} \text { Para fins do disposto nesta Lei, } \\
\text { considera-se: } \\
\text { I-A - saneamento básico - conjunto de serviços, } \\
\text { infraestruturas e instalações operacionais de: } \\
\text { *Mesmo texto }\end{array}$ \\
\hline $\begin{array}{l}\text { a) abastecimento de água potável: constituído } \\
\text { pelas atividades, infra-estruturas e instalações } \\
\text { necessárias ao abastecimento público de água } \\
\text { potável, desde a captação até as ligações prediais } \\
\text { e respectivos instrumentos de medição; }\end{array}$ & $\begin{array}{l}\text { a) abastecimento de água potável, constituído } \\
\text { pelas atividades, pela disponibilização, pela } \\
\text { manutenção, pela infraestrutura e pelas } \\
\text { instalações necessárias ao abastecimento público } \\
\text { de água potável, desde a captação até as ligações } \\
\text { prediais e os seus instrumentos de } \\
\text { medição; } \\
\text { *Em negrito, acréscimos feitos pela MP } n^{o} \\
868 / 2018\end{array}$ \\
\hline $\begin{array}{l}\text { b) esgotamento sanitário: constituído pelas } \\
\text { atividades, infra-estruturas e instalações } \\
\text { operacionais de coleta, transporte, tratamento e } \\
\text { disposição final adequados dos esgotos } \\
\text { sanitários, desde as ligações prediais até o seu } \\
\text { lançamento final no meio ambiente; }\end{array}$ & $\begin{array}{l}\text { b) esgotamento sanitário, constituído pelas } \\
\text { atividades, pela disponibilização e pela } \\
\text { manutenção de infraestrutura e das instalações } \\
\text { operacionais de coleta, transporte, tratamento e } \\
\text { disposição final adequados dos esgotos } \\
\text { sanitários, desde as ligações prediais até a sua } \\
\text { destinação final para a produção de água de } \\
\text { reuso ou o seu lançamento final no meio } \\
\text { ambiente; } \\
\text { *Em negrito, acréscimos feitos pela MP } n^{o} \\
868 / 2018\end{array}$ \\
\hline $\begin{array}{l}\text { c) limpeza urbana e manejo de resíduos sólidos: } \\
\text { conjunto de atividades, infra-estruturas e } \\
\text { instalações operacionais de coleta, transporte, } \\
\text { transbordo, tratamento e destino final do lixo } \\
\text { doméstico e do lixo originário da varrição e } \\
\text { limpeza de logradouros e vias públicas; }\end{array}$ & $\begin{array}{l}\text { c) limpeza urbana e manejo de resíduos sólidos, } \\
\text { constituídos pelas atividades, pela infraestrutura e } \\
\text { pelas instalações operacionais de coleta, } \\
\text { transporte, transbordo, tratamento e destinação } \\
\text { final ambientalmente adequada dos resíduos } \\
\text { sólidos domiciliares e dos resíduos de limpeza } \\
\text { urbanas; } \\
\text { *Em negrito, acréscimos feitos pela MP } n^{o} \\
868 / 2018\end{array}$ \\
\hline $\begin{array}{l}\text { d) drenagem e manejo das águas pluviais, } \\
\text { limpeza e fiscalização preventiva das respectivas } \\
\text { redes urbanas: conjunto de atividades, } \\
\text { infraestruturas e instalações operacionais de } \\
\text { drenagem urbana de águas pluviais, de } \\
\text { transporte, detenção ou retenção para o } \\
\text { amortecimento de vazões de cheias, tratamento e } \\
\text { disposição final das águas pluviais drenadas nas } \\
\text { áreas urbanas. }\end{array}$ & $\begin{array}{l}\text { d) drenagem e manejo das águas pluviais } \\
\text { urbanas, constituídos pelas atividades, pela } \\
\text { infraestrutura e pelas instalações operacionais de } \\
\text { drenagem de águas pluviais, de transporte, } \\
\text { detenção ou retenção para o amortecimento de } \\
\text { vazões de cheias, tratamento e disposição final } \\
\text { das águas pluviais drenadas, contempladas a } \\
\text { limpeza e a fiscalização preventiva das redes. } \\
\text { **Não houve modificação de conteúdo }\end{array}$ \\
\hline
\end{tabular}


Como se pode extrair da transcrição do dispositivo legal, quanto ao alcance semântico do conceito normativo de saneamento básico não houve significativa alteração. Dentre as polêmicas envolvendo o texto da MP em comento é o fim do denominado subsídio cruzado, por meio do qual o fruto da arrecadação com a cobrança de tarifas de água e esgoto, em áreas mais ricas, poderiam ser investidos em municípios com baixo orçamento, ou seja, cidades sem recursos financeiros. O que, segundo entendimento de algumas instituições do setor, "a MP induz operadoras públicas e privadas a competir apenas por municípios superavitários, deixando os deficitários ao encargo dos municípios e estados" (CONSULTOR JURíDICO, 2019). Tal cenário revela violação direta à Constituição Federal de 1988, porquanto isso daria ensejo a situações de desigualdade material, haja vista que a concorrência somente existirá entre os municípios ricos.

Ainda acerca da normativa acima transcrita, que estabelece como saneamento básico no Brasil um conjunto de variadas atividades, envolvendo desde tratamento e coleta de esgoto, a abastecimento de água potável. Ressalte-se, contudo, que é preciso diferenciar os serviços de saneamento básico do direito fundamental ao saneamento básico - embora se imbriquem -, isto porque aqueles (serviços) consubstanciam o aspecto material/executivo das políticas públicas desenvolvidas pelos entes públicos levando em conta a saúde pública etc se abrangente ou limitada a determinadas regiões. Outra coisa é a concretização do direito fundamental ao saneamento básico, cuja ratio essendi é a universalidade; ou seja, um direito de todos e para todos - e não apenas para os que podem pagar pelos serviços ${ }^{6}$.

Destaque-se por relevante que os aspectos de melhoraria e ampliação dos acessos à água boa e ao saneamento básico integram os Objetivos de Desenvolvimento Sustentável (ODS), os quais foram estabelecidos pela Organização das Nações Unidas, em 2015, com vistas a serem alcançados até o ano de 2030 (OPAS-BRASIL, 2019).

Será que o Brasil conseguirá cumprir tais metas? Isso dependerá primordialmente de políticas sérias e de o Estado - de fato - assumir como prioridade as ações para preservação das águas, de implemento das políticas de resíduos sólidos e de saneamento básico - afinal se é básico, deve ser prioridade para sua concretização universal.

Por oportuno e à guisa de ilustração, em outubro de 2018, a Organização Mundial da Saúde (OMS) chamou a atenção para fato de que as metas de implemento universal de esgotamento sanitário só conseguirão alcançar o marco temporal dos objetivos do milênio que é 2030 - se houver mudanças efetivas no plano político que promovam os investimentos necessários para isso.

No Brasil, a questão do saneamento básico começou a ser objeto de maior preocupação por volta da segunda metade do século XIX e início do século XX, especialmente com o crescimento dos polos industriais, os quais trouxeram a reboque processo migratório das áreas rurais, crescimento desordenado das cidades, proliferação de doenças. Nesse cenário, Ney Albert Murtha, José Esteban Castro e Léo Heller pontuam:

As reformas urbanas em diversas cidades brasileiras, entre o final do século XIX e o início do século XX, lançaram as bases do moderno urbanismo brasileiro, em que se implantavam obras viárias, de saneamento básico e embelezamento paisagístico em conjunto com as bases legais para um

\footnotetext{
${ }^{6}$ Em tempo, neste texto não se entrará na questão que envolve a privatização - ou não - dos serviços de saneamento básico, o que será objeto de estudo em outro paper.
} 
mercado imobiliário em termos capitalistas. A população excluída desse processo era expulsa para os morros e para as franjas das cidades. Manaus, Belém, Porto Alegre, Curitiba, Santos, Recife, São Paulo e especialmente o Rio de Janeiro são cidades que passaram, nesse período, por mudanças que conjugaram saneamento ambiental, embelezamento e segregação territorial (MURTHA; CASTRO; HELLER, 2019, p.201-202).

Pelo que se infere do fragmento textual dos autores supra mencionados, o direito ao saneamento básico já nasceu em solo brasileiro sem observar princípios básicos e fundamentais como a igualdade material e a dignidade da pessoa humana, sem os quais não há justiça social, tampouco inclusão socio-econômica.

$\mathrm{O}$ que se verifica das políticas de saneamento básico no início de século XX é que o Brasil não trouxe de fato para si tal questão como fundamental, haja vista que a prestação dos serviços de esgotamento sanitário ficava a cargo da iniciativa privada, cujo objetivo primordial era auferir lucros.

A questão que se coloca hodiernamente é como contemplar o acesso desses serviços essenciais à população hipossuficiente economicamente a partir de uma ótica empresarial? No passado recente do Brasil foi possível constatar mazelas e exclusões quanto aos acessos de água boa e saneamento básico.

De acordo com estudo desenvolvido em parceria entre o Transnational Institute (TNI), o Public Services International Research Unit (PSIRU) e o Multinational Observatory, estima-se que "nos últimos 15 anos houve ao menos 180 casos de remunicipalização do fornecimento de água e esgoto em 35 países, em cidades como Paris (França), Berlim (Alemanha), Buenos Aires (Argentina), Budapeste (Hungria), La Paz (Bolívia) e Maputo (Moçambique)" (ONUBR, 2019). Também nos Estados Unidos muitas cidades avocaram para si os serviços de água, a exemplo de Atlanta e Indianapolis (LOBINA et al, 2019). O estudioso Leo Heler assevera que a privatização desses serviços essenciais não tem sido profícua em muitos países, pois dentre os principais problemas estão as altas tarifas que trazem por consequência exclusão social (ONUBR, 2019).

\section{4. Água potável e saneamento básico: dois direitos que se interconectam}

Segundo relatório da Organização Mundial de Saúde (OMS), a concretização dos direitos à água potável e ao saneamento básico são fundamentais para a boa saúde dos indivíduos. Nesse sentido, dispõe o relatório:

Safe sanitation is essential for health, from preventing infection to improving and maintaining mental and social well-being. The lack of safe sanitation systems leads to infection and disease, including:

- Diarrhoea, a major public health concern and a leading cause of disease and death among children under five years in low-and middleincome countries (Prüss-Üstün et al. 2016);

- Neglected tropical diseases such as soil-transmitted helminth infections, schistosomiasis and trachoma that cause a significant burden globally (WHO, 2017); and

- Vector-borne diseases such as West Nile Virus or lymphatic filariasis (Curtis et al., 2002; van den Berg, Kelly-Hope \& Lindsay, 2013), through poor sanitation facilitating the proliferation of Culex mosquitos. Unsanitary conditions have been linked with stunting (Danaei et al., 2016), which affects almost one quarter of children under-five globally (UNICEF/ WHO/World Bank, 2018) through several mechanisms including repeated diarrhoea 
(Richard et al., 2013), helminth infections (Ziegelbauer et al., 2012) and environmental enteric dysfunction (Humphrey, 2009; Keusch et al., 2014; Crane et al., 2015) (see Box 1.1). The lack of safe sanitation systems contributes to the emergence and spread of antimicrobial resistance by increasing the risk of infectious diseases (Holmes et al., 2016) and thereby use of antibiotics to tackle preventable infections. Inadequate management of faecal waste that includes antimicrobial residues from communities and health care settings can also contribute to emergence of resistance (Korzeniewska et al., 2013; Varela et al., 2013)(WHO, 2019).

Não há dúvida de que os direitos à vida digna, à saúde, à água boa e ao saneamento básico precisam e devem caminhar juntos.

A Lei $n^{\circ}$ 11. 445/2007 (alterada de forma significativa pela MP $n^{\circ} 868 / 2018$ ), instituidora da Política Nacional de Saneamento Básico traz um rol de princípios que revelam a interconexão essencial entre o acesso universal às políticas de saneamento básico e água boa. brasileira:

Nesse sentido, vale realçar alguns daqueles que norteiam a política do saneamento

Art. $3^{\circ}$. Os serviços públicos de saneamento básico serão prestados com base nos seguintes princípios fundamentais:

I - universalização do acesso;

II - integralidade, compreendida como o conjunto de atividades e componentes de cada um dos diversos serviços de saneamento básico, que propicia à população o acesso de acordo com suas necessidades e maximiza a eficácia das ações e dos resultados

III - abastecimento de água, esgotamento sanitário, limpeza urbana e manejo dos resíduos sólidos realizados de forma adequada à saúde pública e à proteção do meio ambiente

IV - disponibilidade, nas áreas urbanas, de serviços de drenagem e manejo das águas pluviais, limpeza e fiscalização preventiva das redes, adequados à saúde pública e à segurança da vida e do patrimônio público e privado

V-A - adoção de métodos, técnicas e processos que considerem as peculiaridades locais e regionais;

[...]

VII - eficiência e sustentabilidade econômica;

VIII - estímulo à pesquisa, ao desenvolvimento e à utilização de tecnologias apropriadas, consideradas a capacidade de pagamento dos usuários, a adoção de soluções graduais e progressivas e a melhoria da qualidade com ganhos de eficiência e redução dos custos para os usuários.

$[\ldots]$

XIII-A - combate às perdas de água, inclusive na distribuição de água tratada, e estímulo à racionalização de seu consumo pelos usuários e fomento à eficiência energética, ao reuso de efluentes sanitários e ao aproveitamento de águas de chuva.

Infelizmente em terra brasilis ainda há muito caminho a trilhar para que tais princípios/normas, previstos no art. $3^{\circ}$ do novel da política nacional de saneamento básico, se concretizem no mundo da vida. Apenas à guisa de ilustração, ressalta-se que enquanto em Tóquio, no Japão, a perda de água chega ao patamar máximo de $2 \%$ (G1, 2019), no Brasil, a perda alcançou em 2017 o percentual de 38,03, de acordo com o Sistema Nacional de Informações sobre Saneamento -SNIS - (BRASIL, 2019). Estudos realizados pelo Instituto 
Trata Brasil, em parceria com GO Associados (INTITUTO TRATA BRASIL 2019) trazem o ranking do saneamento básico no cenário brasileiro de 2018, considerando dados de 2016 do Ministério das Cidades. Com efeito, apesar de o Brasil ter 5.570 municípios, a pesquisa mencionada usou como base metodológica a análise das 100 maiores cidades.

O estudo revelou que das 100 cidades, apenas duas têm serviços universais de coleta de esgoto (Piracicaba, SP; Cascavel, PR). Há outras, como Curitiba (99,99\%), Londrina (99,99\%), Maringá (99,99\%), Ponta Grossa (99,99\%), Santos $(99,88 \%)$, Franca $(99,62 \%)$ e Santo André $(98,77 \%)$ que estão quase lá. Vale destacar que o serviço de coleta é diferente do tratamento de esgoto. Assim, com relação ao tratamento de esgoto, a pesquisa constatou que somente 6 municípios alcançaram o patamar máximo de $100 \%$ de tratamento de esgoto em relação à água consumida. São eles: Jundiaí, Limeira, Niterói, Petrópolis, Piracicaba e Salvador. Outras, no entanto, estão muito abaixo do desejado em termos de tratamento de esgoto Nesse rol estão Duque de Caxias, com 3,89 \%, Bauru, com 3,44\%, Belém, com 2,67\%, Guarulhos com 2,12\%, Porto Velho, com 1,54\%, Santarém, com 1,39\%, e Ananindeua, Governador Valadares, Nova Iguaçu, São João de Meriti com 0,91\% (INTITUTO TRATA BRASIL' 2019)

A realidade brasileira revela que em termos de saneamento básico ainda estamos engatinhando. E não há como pensar em saúde pública, água boa e meio ambiente equilibrado sem que haja efetivamente a implementação de todos os serviços que enfeixam o conceito normativo de saneamento básico, previsto na Lei no 11. 445/2007.

Por oportuno, vale fazer menção ao Projeto de Lei n. 3.261/2019, que alterará - se aprovado - o diploma normativo da Política Nacional de Saneamento Básico, a Lei n. 11.445/2007. O mesmo está tramitando no Congresso Nacional e traz algumas novidades que mudarão a atual face estrutural dos serviços de saneamento no Brasil. Apesar de sua importância, a sua análise se dará em outro texto.

\section{Conclusão}

Á guisa de simples conclusão, uma vez que a temática aqui trazida está longe de se chegar a uma conclusão digna para todos os seres vivos (pessoas, fauna e flora)

Não restam dúvidas de que a preocupação com a concretude dos direitos à água potável e ao saneamento básico é vigorosamente justificada, quando se constata a exaustão da natureza, a despeito de sua resiliência, causada por variados agentes poluentes, usos demasiados e nem sempre responsáveis e sustentáveis.

Nesse sentido, defende-se que a natureza (no caso deste estudo, a água) possa ser sujeito de direitos e titular de dignidade, como forma de se buscar mudanças de paradigmas.

Ainda, as políticas de saneamento básico e de resíduos sólidos deveriam ser questão de Estado e não apenas de governo, porquanto o implemento de tais políticas consubstancia conditio sine qua non para a qualidade das águas e essencial para a vida do e no planeta.

\section{REFERÊNCIAS}

BARLOW, Maude; CLARKE, Tony. Ouro Azul. $1^{\circ}$ ed. São Paulo. M. Books do Brasil Editora Ltda, 2003.

BRASIL. Lei $\mathbf{n}^{\circ}$ 11.445, de 05 de janeiro de 2007. Estabelece diretrizes nacionais para o saneamento básico; altera as Leis $\mathrm{n}^{\text {os }} 6.766$, de 19 de dezembro de 1979, 8.036, de 11 de maio de 1990, 8.666, de 21 de junho de 1993, 8.987, de 13 de fevereiro de 1995; revoga a Lei ${ }^{\circ}$ 6.528, de 11 de maio de 1978; e dá outras providências. Disponível em < http://www.planalto.gov.br/ccivil_03/_ato2007-2010/2007/lei/111445.htm>. Acesso em 03.04.2018. 
BRASIL. Lei $\mathbf{n}^{\mathbf{0}}$ 12.305, de 02 de agosto de 2017. Instituiu a Política Nacional de Resíduos Sólidos; altera a Lei $\mathrm{n}^{\circ}$ 9.605, de 12 de fevereiro de 1998; e dá outras providências. Disponível em <http://www.planalto.gov.br/ccivil_03/_ato2007-2010/2010/lei/112305.htm>. Acesso em 20.05.2018.

BRASIL. Sistema Nacional de Informações sobre Saneamento (SNIS). Ministério do Desenvolvimento Regional publica diagnósticos da situação do saneamento no Brasil. Disponível em < http://www.snis.gov.br>. Acesso em 15.01.2020.

BULOS, Uadi Lammego. Curso de Direito Constitucional. 5 ed. São Paulo: Editora Saraiva, 2019.

CARLI, Ana Alice De. VASCONCELlOS, Thaís Freire De. Saneamento básico e água potável: a correlação necessária na seara da proteção dos direitos da natureza. In: MORATO, José L.; PERALTA, Carlos E.; CARLI, Ana Alice De (orgs.). Água y Saneamiento Básico en el Siglo XXI: Brasil y Costa Rica. Costa Rica: Ed. UCR, 2018, p. 95-116.

CARLI, Ana Alice De. A água e seus instrumentos de efetividade: educação ambiental, normatização, tecnologia e tributação. $1^{\circ}$ ed. Campinas, SP: Editora Millennium, 2013.

CARLI, Ana Alice De. Educação ambiental: condição fundamental à concretização da política nacional das águas brasileiras.. In: CARLI, Ana Alice De; MARTINS, Saadia Borba (orgs.). Educação Ambiental: premissa inafastável ao desenvolvimento econômico sustentável. Rio de Janeiro: Ed. Lumen Juris, 2014, p. 9-34.

CARLI, Ana Alice De. A sustentabilidade dos recursos hídricos como condição de possibilidade à preservação desta riqueza. In: AVZARADEL, Pedro C.S. et al (org). Constituição, crise hídrica, energia e mineração na América Latina. Rio de Janeiro: Ed. Lumen Juris, 2015.

CARVALHO, Vinícius Marques de. O Direito do Saneamento Básico - Coleção Direito Econômico e Desenvolvimento - Volume1. São Paulo: Quartier Latin, 2010.

CAVINATTO, Vilma Maria. Saneamento básico: fonte de saúde e bem-estar. 2. ed. - São Paulo: Moderna, 2003.

CHACHÉ, Cristiane Borborema. A disputa pela titularidade do serviço público de saneamento no Brasil: comentários sobre os conflitos que ainda persistem. In: MORATO, José L.; PERALTA, Carlos E.; CARLI, Ana Alice De (orgs.). Água y Saneamiento Básico en el Siglo XXI: Brasil y Costa Rica. Costa Rica: Ed. UCR, 2018, p. 189-207.

COMITÊ MÉDIO PARAÍBA. Atlas Região Hidrográfica Médio Paraíba do Sul. Disponível em: <http://www.cbhmedioparaiba.org.br/conteudo/atlas-CBH-MPS.pdf>. Acesso em: 29.05.2018.

CONSULTOR JURÍDICO. Medida controversa: Temer publica MP que altera marco legal do saneamento básico no país. Disponível em www.conjur.com.br/2018-dez-28/temerpublica-mp-altera-marco-legal-saneamento-basico. Acesso em 15.03.2019.

CORREIO BRAZILIENSE. 'Cada real investido em saneamento básico gera economia de R\$ 4 em gastos em saúde', diz professora - Doenças relacionadas ao mau uso da água causam 3,5 milhões de mortes por ano na América Latina, na África e na Ásia. Correio Debate. Disponível em

https://www.correiobraziliense.com.br/app/noticia/correiodebate/desafiohidrico/2017/04/18/n oticias-desafiohidrico,589136/dinheiro-investido-em-saneamento-basico-gera-economia-emsaude.shtml. Acesso em 27.02.2019.

DECLARAÇÃO DOS DIREITOS DA ÁGUA. Disponível em www.ecolnews.com.br. Acesso em: 23/02/2019. 
FINGER, Matthias; ALLOUCH,Jeremy. Water Privatisation: Trans-National Corporations and the Re-Regulation of the Water Industry. Disponivel em www.researchgate.net/profile/Jeremy_Allouche/publication/37408336_Water_Privatisation_T rans-National_Corporations_and_the_Re-

Regulation_of_the_Water_Industry/links/543912920cf204cab1d7db96/Water-PrivatisationTrans-National-Corporations-and-the-Re-Regulation-of-the-Water-

Industry.pdf?origin=publication_detail. Acesso em 09.03.2019.

G1. Tóquio ú é uma das cidades menos desperdiça água no mundo: capital do Japão dá exemplo com equipamentos simples e constante fiscalização, além do combate ao desperdício, que não passa de $2 \%$. Disponível em http://g1.globo.com/jornal-nacional/noticia/2015/02/toquio-e-uma-das-cidades-que-menosdesperdica-agua-no-mundo.html. Acesso em 15.03.2019.

GASPAR, Alberto. Área desértica no Chile enfrenta desafios no abastecimento de água. G1. Disponível em < http://g1.globo.com/jornal-hoje/noticia/2012/06/area-desertica-no-chileenfrenta-desafios-no-abastecimento-de-agua.html> .Acesso em 27.02.2019.

GO ASSOCIADOS. Perdas de água 2018 (SNIS 2016): desafios para disponibilidade hídrica e avanço da eficiência do saneamento básico. Disponível em: http://www.tratabrasil.org.br/images/estudos/itb/perdas-2018/estudo-completo.pdf. Acesso em 15.01.2020.

GRAÇA, Guilherme Mello. ALMEIDA, Ana Paula De. Distribuição e Conflitos de Competência no Âmbito Do Saneamento Básico: Município como Ente Titular na Prestação do Serviço. In: André Saddy, Rodrigo da Fonseca Chauvet (coordenadores). Aspectos Jurídicos do saneamento básico. $1^{\circ}$ ed. Rio de Janeiro: Lumen Juris, 2017.

GRAU, Eros Roberto. Ensaio e Discurso sobre a Interpretação do Direito. 5 ed. São Paulo: Editora Malheiros, 2009.

GUSSOLI, Felipe Klein. A natureza como sujeito de direito na Constituição do Equador: considerações a partir do caso Vilcabamba. Disponível em <http://www.direito.ufpr.br/portal/wp-content/uploads/2014/12/Artigo-Felipe-Gussoli-

classificado-em-1\%C2\%BA-lugar-. pdf >. Acesso em 05.06.2019.

HARDING, Stephan. Terra Viva: ciência, intuição e a evolução de gaia. Tradução de Mario Molina. São Paulo: Editora Cultriz, 2008.

INTITUTO TRATA BRASIL. Ranking do Saneamento 2018. Disponível em < http://www.tratabrasil.org.br>. Acesso em 16.12.2019.

LOBINA, Emanuele; KISHIMOTO, Satoko; Petitjean, Olivier. Here to stay: water remunicpalisation as a global trend. Disponível em <https://multinationales.org/Here-tostay-Water>. Acesso em 14.12.2019.

MENEZES, L. C. C. Considerações sobre saneamento básico, saúde pública e qualidade de vida. Revista Engenharia Sanitária e Ambiental, Rio de Janeiro, v.23, n.1, jan./mar., p. 5561, 1984.

MURTHA, Ney Albert; CASTRO, José Esteban; HELLER, Léo. Uma perspectiva histórica das primeiras políticas públicas de saneamento e de recursos hídricos no Brasil. Revista Ambiente e Sociedade. Vol. XVII, $\mathrm{n}^{\circ}$ 3. Disponível em < http://www.scielo.br/pdf/asoc/v18n3/1809-4422-asoc-18-03-00193.pdf >. Acesso em 07.01.2020.

ONUBR. Privatização do saneamento já se mostrou inadequada em muitos países, diz relator da ONU. Disponível em < https://nacoesunidas.org/privatizacao-do-saneamento-ja- 
se-mostrou-inadequada-em-muitos-paises-diz-relator-da-onu/>. Acesso em 09.12.2019. OPAS BRASIL. 2,1 bilhões de pessoas não têm água potável em casa e mais do dobro não dispõem de saneamento seguro. Disponível em < https://www.paho.org/bra/index.php?option=com_content $\&$ view=article \&id=5458:oms-2-1bilhoes-de-pessoas-nao-tem-agua-potavel-em-casa-e-mais-do-dobro-nao-dispoem-desaneamento-seguro\&Itemid=839>. Acesso em 27.12.2019.

OPAS-BRASIL. Objetivos de Desenvolvimento Sustentável (ODS). Disponível em https://www.paho.org/bra/index.php?option=com_content\&view=article\&id=5849:objetivosde-desenvolvimento-sustentavel\&Itemid=875. Acesso em 28.02.2019.

OPAS-OMS. OMS pede aumento de investimentos para atingir meta de banheiro para todos.

https://www.paho.org/bra/index.php?option=com_joomlabook\&view=topic\&id=522. Acesso em 28.02.2019.

ONG PACHAMAMA. Em ação judicial inédita no Brasil, o Rio Doce, representado pela Associação Pachamama, pede o reconhecimento de seus direitos à vida e a saúde. Disponível em: www.ongpachamama.org/single-post/2017/11/07/Umaa\%C3\%A7\%C3\%A3o-pelos-rios-como-sujeitos-de-direito. Acesso em 27.05.2019.

ONU. Água potável: direito humano fundamental. 2010. Disponível em: < https://nacoesunidas.org/>. Acesso em 01.02.2020.

PERALTA, Carlos E. Perspectivas do estado de direito ambiental no antropoceno. Revista Internacional de Direito Ambiental - Ano III, n.8 (maio/ago. 2014). Caxias do Sul, RS: Plenum, 2014.

PERALTA, Carlos E. Água e Saneamento básico no antropoceno: estado atual e desafios para a Costa Rica. In: MORATO, José L.; PERALTA, Carlos E.; CARLI, Ana Alice De (orgs.). Água y Saneamiento Básico en el Siglo XXI: Brasil y Costa Rica. Costa Rica: Ed. UCR, p. 21-56.

PERLINGIERI, Pietro. Perfis do Direito Civil. Tradução de Maria Cristina De Cicco. $3^{\mathrm{a}}$ ed. Rio de Janeiro: Ed. Renovar, 2002.

SABADELL, Ana Lucia. Manual de Sociologia Jurídica: introdução a uma leitura externa do Direito. 4 ed. rev.atual.ampl. São Paulo: Editora Revista dos Tribunais, 2008.

SENADO FEDERAL. Proposta de Emenda À Constituição no 2 de 2016. Disponível em: $<$ http://www25.senado.leg.br/web/atividade/materias/-/materia/124779>. Acesso em 20.05.2018.

UN. Resolução no 12/8 - Human rights and access to safe drinking water and sanitation. Disponível em: www.un.org/ga/search/view_doc.asp?symbol=A/HRC/RES/12/8. Acesso em 05.02.2019.

UN. Resolução $\quad$ n. $64 / 292$ Disponível www.un.org/ga/search/view_doc.asp?symbol=A/RES/64/292. Acesso em 01.02.2020.

UN. $\quad$ Res. $\quad 70 / 169 . \quad$ Disponível http://www.un.org/en/ga/search/view_doc.asp?symbol=A/RES/70/169>. Acesso em 27.12.2019.

UNIESP. Declaração de Direitos do Bom Povo de Virgínia. 16 de Junho de 1776. Disponível em: uniesp.edu.br/sites/_biblioteca/revistas/20170725113835.pdf. Acesso em 29.03.2019.

UNWATER. Relatório Mundial das Nações Unidas sobre o Desenvolvimento dos Recursos Hidrícos 2017. Disponível em: 
unesdoc.unesco.org/images/0024/002475/247553por.pdf. Acesso em 05.05.2019.

VIANA, Matheus Gomes. A Terra como sujeito de direitos. Revista da Faculdade de Direito, Fortaleza, v. 34, n. 2, p. 247-275, jul./dez. 2013. Disponível em: <http://www.revistadireito.ufc.br/index.php/revdir/article/viewFile/106/87>. Acesso em 29.05.2019.

VIOLA, Eduardo. O movimento ecológico no Brasil (1974-1986): do ambientalismo à ecopolítica. In: PADUA, José Augusto; VIOLA, Eduardo; MINC, Carlos; VIEIRA, Liszt; GABEIRA, Fernando; GONZAGA, Paulo (org.). Ecologia e Política no Brasil. $2^{a}$ ed. Rio de Janeiro: Ed. Espaço e Tempo; Iuperj, 1987, p. 63-110.

WHO. Guidelines on sanitation and health. Disponível em https://apps.who.int/iris/bitstream/handle/10665/274939/9789241514705-eng.pdf?ua=1. Acesso em 28.12.2019.

WOM. The Dublin statement on water and sustainable development. Disponível em: www.wmo.int/pages/prog/hwrp/documents/english/icwedece.html. Acesso em: 05.05.2019. 